\title{
РАДІАЦІЙНІ ВТРАТИ У ПЛАНАРНОМУ СВІТЛОВОДІ ЗІ ШОРСТКОЮ МЕЖЕЮ ПОДІЛУ ДІЕЛЕКТРИЧНИХ ШАРІВ
}

\author{
О.Г. МАТЕВОСОВА, А.В. КОВАЛЕНКО, В.Н. КУРАШОВ
}

УдК 535.43
(C)2012

Київський національний університет ім. Тараса Шевченка

(Вул. Володимирсъка, 64, Kuїв 01033; e-mail: matyevosova. lena@gmail. com)

Розвинуто статистичну модель розсіювання світла шорсткою поверхнею планарного світловода, вільну від наближення слабонаправленого світловода. Досліджено залежність величини втрат від висоти профілю показника заломлення, товщини серцевини світловода та кореляційних характеристик розсіюючої поверхні. Проаналізовано відмінності розсіювання ТЕ та ТМ мод, показано, що двовимірна модель непридатна для кількісних оцінок втрат у випадку ТМ мод.

\section{1. Вступ}

Поширення світла у діелектричних світловодах із нерегулярними границями діелектричних шарів супроводжується радіаційними втратами, що викликаються розсіюванням світла шорсткою поверхнею. Це явище відоме давно, проте воно довгий час залишалось поза увагою дослідників, що працювали у галузі волоконної оптики. Це, ймовірно, пов'язано $з$ тим, що сила такого розсіювання $є$ пропорційною висоті профілю показника заломлення світловода, а тому виявляється нехтовно малою у слабонаправлених світловодах. Саме такі світловоди довгий час знаходились у центрі уваги, оскільки у них легко реалізувати одномодовий режим поширення світла, що $є$ бажаним у більшості застосувань. Цікавість до поверхневого розсіювання значно зросла у зв'язку з процесом мініатюризації оптичних елементів, створенням структур субмікронного та наномасштабу. Зменшення характерних розмірів оптичних хвилеводів можливе лише за умови адекватного збільшення різниці показників заломлення діелектричних шарів хвилеводної структури, що супроводжується зростанням ролі поверхневого розсіювання. Теоретично та експериментально показано, що абсолютні значення таких втрат можуть бути істотними, зокрема у фотоннокристалічних світловодах [1], нановолокнах [2], планарних хвилеводних компонентах інтегральної оптики $[3,4]$.

Доцільність дослідження поверхневого розсіювання у планарних світловедучих структурах зумовлена низкою обставин. По-перше, прості граничні умови дозволяють знайти аналітичні розв'язки відповідних електродинамічних задач, що спрощує аналіз впливу статистичних дефектів структури. 3 іншого боку, при виготовленні плоских хвилеводних шарів застосовуються принципово різні технологічні процеси, які характеризуються різними фізичними механізмами утворення дефектів поверхні, що дає можливість експериментально визначити вплив статистики неоднорідностей на ефективність розсіювання. Нарешті, плоска геометрія об'єкта практично виключає вплив згинів та неконтрольованих змін товщини хвилеводного шару на розсіювання світла, що особливо характерне для циліндричних нанорозмірних волокон.

У даній роботі розвинуто статистичну модель розсіювання світла шорсткою поверхнею планарного світловода, вільну від наближення слабонаправленого світловода. Головною особливістю запропонованого підходу є застосування нелінійної моделі формування еквівалентних вимушених струмів на статистично неоднорідній поверхні, яка дозволяє детально дослідити залежність величини втрат від висоти профілю показника заломлення, товщини серцевини світловода та кореляційних характеристик розсіюючої поверхHi. 


\section{2. Радіаційні втрати у наближенні слабко збуреної межі поділу у світловоді}

Розглянемо модель планарного світловода, одна з границь якого має випадковий рельєф, що виступає у вигляді однорідного гаусівського поля $\xi(z)$, таке, що його середнє значення $\langle\xi\rangle=0$, кореляційна функція $\left\langle\xi^{*}\left(z_{1}\right) \xi\left(z_{2}\right)\right\rangle=G_{\xi}\left(z_{2}-z_{1}\right) \equiv G_{\xi}(\Delta z)$ i ceредньоквадратичне відхилення $\sigma_{\xi} \ll \rho$ (рис. 1). Значення поля $\xi(z)$ у певній точці $z$ дорівнює величині відхилення границі середовищ із різними показниками заломлення (на рис. 1 поле $\xi(z)$ відраховується від точки $\rho$ по осі $O x)$.

Показник заломлення подамо у вигляді суми двох складових:

$n^{2}(x, z)=n_{0}^{2}(x)+n_{1}^{2}(x, z)$,

де $n_{0}(x)$ - показник заломлення незбуреного хвилеводу, а друга складова залежить від значення поля $\xi(z)$ :

$n_{1}^{2}(x, z)= \begin{cases}n_{c o}^{2}-n_{c l}^{2}, & \xi(z)>x-\rho \\ n_{c l}^{2}-n_{c o}^{2}, & \xi(z)<x-\rho \\ 0, & \text { в інших випадках }\end{cases}$

де $n_{c o}$ i $n_{c l}$ - показники заломлення серцевини і оболонки відповідно, $\rho$ - півширина серцевини хвилеводу (рис. 1).

Збурення коефіцієнта заломлення локалізоване у тонкому шарі біля межі поділу $x=\rho$, в межах якого можна вважати, що поля не змінюються, причому тангенціальні компоненти електричного поля $e_{z}(\rho)$, $e_{y}(\rho)$ неперервні на границі, а компонента $e_{x}$ на границі має розрив: $e_{x}(\rho+0)$ при $x>\rho$ та $e_{x}(\rho-0)$ при $x<\rho$.

Відповідно до стандартної процедури [5] замінимо збурений хвилевод на незбурений з вимушеними джерелами струмів. Оскільки $\sigma_{\xi} \ll \rho$, поля у збуреному хвилеводі мало відрізняються від полів у незбуреному, тому можна застосувати метод теорії малих збурень, а саме: подати електричне поле у вигляді

$\bar{E}_{0}(x, z)=\bar{E}_{0}^{(0)}(x, z)+\bar{E}_{0}^{(1)}(x, z)$,

де $\bar{E}_{0}^{(0)}(x, z)=a_{0} \bar{e}_{0}(x) e^{j \beta_{0} z}-$ поле у незбуреному хвилеводі $\left(a_{0}-\right.$ амплітудний коефіцієнт моди, що поширюється, а $\beta_{0}$ - їі стала поширення),

$\bar{E}_{0}^{(1)}(x, z)=\int_{0}^{Q_{\max }} a_{\mathrm{ITE}}(Q, z) \bar{e}_{\mathrm{ITE}}(x, Q) e^{j \beta_{\mathrm{ITE}}(Q) z} d Q+$

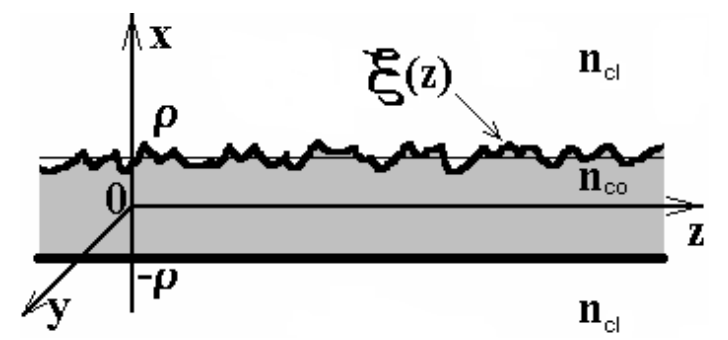

Рис. 1. Планарний світловод із збуреним інтерфейсом серцевина/оболонка

$+\int_{0}^{Q_{\max }} a_{\mathrm{ITM}}(Q, z) \bar{e}_{\mathrm{ITM}}(x, Q) e^{j \beta_{\mathrm{ITM}}(Q) z} d Q$

- сумарне поле мод випромінювання, причому $\bar{E}_{0}^{(1)}(x, z) \ll \bar{E}_{0}^{(0)}(x, z)$. Тут введено такі позначення: $a_{\mathrm{ITE}}, a_{\mathrm{ITM}}-$ амплітудні коефіцієнти мод випромінювання, $\bar{e}_{\mathrm{ITE}}(x, Q), \bar{e}_{\mathrm{ITM}}(x, Q)$ - значення електричного поля мод випромінювання (див. таблицю), $\beta_{\text {ITE }}, \beta_{\text {ITM }}$ - сталі поширення мод випромінювання, $Q^{2}=\rho^{2}\left(k^{2} n_{c l}^{2}-\beta_{\text {ITE,ITM }}^{2}\right), Q_{\max }=\rho k n_{c l}$. ITE та ITM позначають, відповідно, поперечну магнітну та поперечну електричну моди випромінювання.

Вирази для компонент магнітного поля аналогічні виразам (3), (4).

Підставивши вирази для полів (3), (4) у рівняння Максвелла та нехтуючи доданками порядку вищого за перший, отримаємо додатковий член у рівнянні Максвелла, який можна трактувати як вимушений струм:

$\bar{J}_{0}(x, z)=-j \sqrt{\frac{\varepsilon_{0}}{\mu_{0}}} k n_{1}^{2}(x, z) a_{0} \bar{e}_{0}(x) e^{j \beta_{0} z}$

де $k$ - хвильовий вектор хвилі у вакуумі. Згідно $з$ [5] амплітудні коефіцієнти мод випромінювання для густини струму $\bar{J}_{0}$ дорівнюють

$a_{\mathrm{ITE}}(Q, z)=-\frac{1}{4 N_{\mathrm{ITE}}(Q)} \int_{0}^{z} \int_{-\infty}^{\infty} \bar{e}_{\mathrm{ITE}}^{*} \times$

$\times \bar{J}_{0}\left(x, z^{\prime}\right) e^{-j \beta_{\mathrm{ITE}} z^{\prime}} d x d z^{\prime}$

де $N_{\text {ITE }}(Q)$ - нормуючий множник ITE моди (табл. 1). Вираз для амплітуд $a_{\mathrm{ITM}}$ ITM мод $є$ аналогічним з заміною $N_{\text {ITE }} \rightarrow N_{\mathrm{ITM}}, e_{\mathrm{ITE}} \rightarrow e_{\mathrm{ITM}}$, $\beta_{\text {ITE }} \rightarrow \beta_{\text {Iтм}}$. Оскільки можна вважати поля сталими у збуреному шарі, після відповідних спрощень отри- 


\begin{tabular}{|c|c|c|c|c|}
\hline Тип моди & Компо & оненти електричного поля & Параметри $a, b$ & Нормування \\
\hline ITM непарні & $\begin{array}{c}e_{z}(x)=\frac{j}{k \rho n^{2}(x)} \\
e_{x}(x)=\frac{\beta}{k n^{2}(x)}\end{array}$ & $\begin{array}{l} \begin{cases}Q \cos Q\left(\frac{x}{\rho}-1\right)+a, & x>\rho \\
b U \cos \frac{U x}{\rho}, & -\rho<x<\rho \\
Q \cos Q\left(\frac{x}{\rho}+1\right)-a, & x<\rho\end{cases} \\
\begin{cases}\sin Q\left(\frac{x}{\rho}-1\right)+a, & x>\rho \\
b \sin \frac{U x}{\rho}, & -\rho<x<\rho \\
\sin Q\left(\frac{x}{\rho}+1\right)-a, & x<\rho\end{cases} \end{array}$ & $\begin{array}{c}\tan a=\frac{n_{c o}^{2} Q}{n_{c l}^{2} U} \tan U \\
b=\frac{\sin a}{\sin U}\end{array}$ & \multirow[t]{2}{*}{$\frac{1}{2} \int_{-\infty}^{\infty}\left[\bar{e}_{j}(Q) \times \bar{h}_{j}^{*}\left(Q^{\prime}\right)\right] \hat{z} d x=$} \\
\hline ITM парні & $\begin{array}{c}e_{z}(x)=-\frac{j}{k \rho n^{2}(x)} \\
e_{x}(x)=\frac{\beta}{k n^{2}(x)}\end{array}$ & $\begin{array}{c} \begin{cases}Q \sin Q\left(\frac{x}{\rho}-1\right)+a, & x>\rho \\
b U \sin \frac{U x}{\rho}, & -\rho<x<\rho \\
Q \sin Q\left(\frac{x}{\rho}+1\right)-a, & x<\rho\end{cases} \\
\begin{cases}\cos Q\left(\frac{x}{\rho}-1\right)+a, & x>\rho \\
b \cos \frac{U x}{\rho}, & -\rho<x<\rho \\
\cos Q\left(\frac{x}{\rho}+1\right)-a, & x<\rho\end{cases} \end{array}$ & $\begin{array}{c}\tan a=\frac{n_{c l}^{2} U}{n_{c o}^{2} Q} \tan U \\
b=\frac{\cos a}{\cos U}\end{array}$ & \\
\hline ITE непарні & $e_{y}(x)=$ & $\begin{array}{ll}\sin Q\left(\frac{x}{\rho}-1\right)+a, & x>\rho \\
b \sin \frac{U x}{\rho}, & -\rho<x<\rho \\
\sin Q\left(\frac{x}{\rho}+1\right)-a, & x<\rho \\
\end{array}$ & $\tan a=\frac{Q}{U} \tan U, b=\frac{\sin a}{\sin U}$ & \multirow[t]{2}{*}{$N_{\mathrm{ITE}}=\frac{\pi \rho \beta}{2 k} \sqrt{\frac{\varepsilon_{0}}{\mu_{0}}}$} \\
\hline ITE парні & $e_{y}(x)=$ & $\begin{array}{ll}\cos Q\left(\frac{x}{\rho}-1\right)+a, & x>\rho \\
b \cos \frac{U x}{\rho}, & -\rho<x<\rho \\
\cos Q\left(\frac{x}{\rho}+1\right)-a, & x<\rho\end{array}$ & $\tan a=\frac{U}{Q} \tan U, b=\frac{\cos a}{\cos U}$ & \\
\hline
\end{tabular}

мaємo

$a_{\mathrm{ITE}}(Q, z)=\sqrt{\frac{\varepsilon_{0}}{\mu_{0}}} \frac{j k a_{0}}{4 N_{\mathrm{TE}}(Q)} \int_{0}^{z} f_{\mathrm{ITE}}(\xi(z)) \times$

$\times \exp \left(j\left(\beta_{0}-\beta_{\mathrm{ITE}}(Q)\right) z^{\prime}\right) d z^{\prime}$

де $N_{\mathrm{TE}}-$ нормуючий множник ТЕ моди,

$N_{\mathrm{TE}}=\frac{\rho \beta_{0}}{2 k} \sqrt{\frac{\varepsilon_{0}}{\mu_{0}}} \frac{V^{2}}{U^{2}} \frac{1+W}{W}$,

$f(\xi(z))=e_{\mathrm{ITE}}^{*}\left(x_{0}\right) \bar{e}_{0}\left(x_{0}\right)\left(n_{c o}^{2}-n_{c l}^{2}\right) \xi(z)$

$V=\rho k \sqrt{n_{c o}^{2}-n_{c l}^{2}}, \quad U^{2}=\rho^{2}\left(k^{2} n_{c o}^{2}-\beta_{0}^{2}\right)$,

$W^{2}=V^{2}-U^{2}$

Потужність, що втрачається на довжині $z$ ITE модою на шорсткій поверхні, дорівнює:

$p_{\mathrm{ITE}}(Q)=\frac{N_{\mathrm{ITE}}(Q)}{2}\left\langle\left|a_{\mathrm{ITE}}\right|^{2}\right\rangle$.

Перейшовши до різницевих координат $\Delta z=z^{\prime \prime}-z^{\prime}$, $Z=\frac{z^{\prime}+z^{\prime \prime}}{2}$ та маючи на увазі, що $\left\langle f^{*}\left(\xi\left(z^{\prime}\right)\right) f\left(\xi\left(z^{\prime \prime}\right)\right)\right\rangle=$
$=G_{f}(\Delta z)$, остаточно отримаємо

$p_{\mathrm{ITE}}(Q)=\frac{\varepsilon_{0} k^{2} a_{0}^{2} z N_{\mathrm{ITE}}(Q)}{32 \mu_{0} N_{\mathrm{TE}}^{2}(Q)} \int_{-\infty}^{\infty} G_{f_{\mathrm{ITE}}}(\Delta z) \times$

$\times e^{j\left(\beta_{0}-\beta_{\mathrm{ITE}}(Q)\right) z} d(\Delta z)$

і аналогічно для втрат потужності ITM мод із заміною $N_{\mathrm{ITE}} \rightarrow N_{\mathrm{ITM}}, N_{\mathrm{TE}} \rightarrow N_{\mathrm{TM}}, f_{\mathrm{ITE}} \rightarrow f_{\mathrm{ITM}}$, $\beta_{\mathrm{ITE}} \rightarrow \beta_{\mathrm{ITM}}$.

\section{3. Залежність потужності втрат від кореляції збурення поверхні}

Зв'язок між кореляційними функціями $G_{f}$ та $G_{\xi}$ за теоремою Прайса можна подати у вигляді

$\frac{d^{2} G_{f}}{d \gamma_{\xi}^{2}}=G_{f}^{2}(0)\left\langle\frac{d^{2} f^{*}}{d \xi^{2}\left(z^{\prime}\right)} \frac{d^{2} f}{d \xi^{2}\left(z^{\prime \prime}\right)}\right\rangle$,

$\frac{d^{2} G_{f}}{d \gamma_{\xi}^{2}}=\left|m_{c l}-m_{c o}\right|^{2} \frac{\sigma_{\xi}^{2}}{2 \pi \sqrt{1-\gamma_{\xi}^{2}(\Delta z)}}$,

де для зручності введено позначення

$m_{c l}=\left(n_{c o}^{2}-n_{c l}^{2}\right) \bar{e}_{\mathrm{ITE}}^{*}(\rho+0) \bar{e}_{0}(\rho+0) ;$

ISSN 2071-0194. Укр. фіз. журн. 2012. T. 57, №3 
$m_{c o}=\left(n_{c o}^{2}-n_{c l}^{2}\right) \bar{e}_{\mathrm{ITE}}^{*}(\rho-0) \bar{e}_{0}(\rho-0)$.

Розв'язавши рівняння (11) з початковими умовами

$G_{f}\left(\gamma_{\xi}=0\right)=|\langle f\rangle|^{2}$

$G_{f}\left(\gamma_{\xi}=1\right)=\left|\langle f\rangle^{2}\right|$

отримаємо залежність усередненого квадрата модуля амплітудного коефіцієнта ITE мод від кореляції поля збурення:

$G_{f}\left(\gamma_{\xi}\right)=\frac{\sigma_{\xi}^{2}}{4}\left|m_{c l}+m_{c o}\right|^{2} \gamma_{\xi}+$

$+\frac{\sigma_{\xi}^{2}}{2 \pi}\left|m_{c l}-m_{c o}\right|^{2}\left(\gamma_{\xi} \arcsin \gamma_{\xi}+\sqrt{1-\gamma_{\xi}^{2}}\right)$.

Другий доданок у (14)

$f\left(\gamma_{\xi}\right)=\frac{2}{\pi-2}\left(\gamma_{\xi} \arcsin \gamma_{\xi}+\sqrt{1-\gamma_{\xi}^{2}}-1\right)$

добре апроксимується квадратичною функцією $\gamma_{\xi}^{2}$ (рис. 2).

Врахувавши це, матимемо

$G_{f}\left(\gamma_{\xi}\right)=\frac{G_{\xi}(\Delta z)}{4}\left|m_{c l}+m_{c o}\right|^{2}+$

$+\frac{\pi-2}{4 \pi}\left|m_{c l}-m_{c o}\right|^{2}\left(\frac{G_{\xi}^{2}(\Delta z)}{G_{\xi}(0)}+G_{\xi}(0)\right)$.

Оскільки $S_{\xi}^{\mathrm{ITE}}(\beta)=\int_{-\infty}^{\infty} G_{\xi} e^{j \beta_{\mathrm{ITE}} \Delta z}$, вираз для розсіяної потужності набуває такого вигляду:

$p_{\text {ITE }}(Q)=A_{1} S_{\xi}^{\mathrm{ITE}}\left(\beta_{0}-\beta_{\mathrm{ITE}}(Q)\right)+$

$A_{2} \int_{-\infty}^{\infty} S_{\xi}^{\mathrm{ITE}}\left(\beta^{\prime}\right) S_{\xi}^{\mathrm{ITE}}\left(\beta_{0}-\beta_{\mathrm{ITE}}(Q)-\beta^{\prime}\right) d \beta^{\prime}$

де

$A_{1}=C\left|m_{c l}+m_{c o}\right|^{2}$,

$A_{2}=C(\pi-2)\left|m_{c l}-m_{c o}\right|^{2} /\left(\pi \sigma_{\xi}^{2}\right)$,

$C=\varepsilon_{0} k^{2} a_{0}^{2} z /\left(128 \mu_{0} N_{\mathrm{TE}}(Q)\right)$

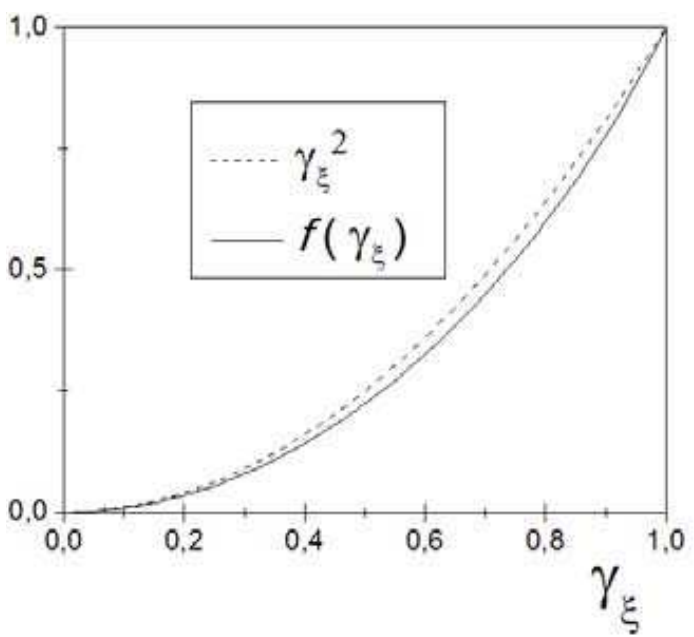

Рис. 2. Порівняння залежностей $f\left(\gamma_{\xi}\right)$ та $\gamma_{\xi}^{2}$ від коефіцієнта кореляції $\gamma_{\xi}$

Аналогічний вираз справедливий і для ITM мод 3 відповідною заміною позначень.

Загальні втрати на випромінювання $P_{\operatorname{rad}}(z)$ знаходяться шляхом інтегрування по всіх модах випромінювання:

$P_{\mathrm{rad}}=\int_{0}^{Q_{\max }} p_{\mathrm{ITE}}(Q) d Q+\int_{0}^{Q_{\max }} p_{\mathrm{ITM}}(Q) d Q$.

Формула (17) справедлива за умови $P_{\text {rad }} \ll P_{\text {tot }}$, тобто при малих довжинах $z$. Тому для розрахунку втрат потужності при як завгодно великих значеннях $z$ необхідно ввести коефіцієнт затухання на одиницю довжини:

$\eta=-\frac{10}{z} \lg \left(1-\frac{P_{\mathrm{rad}}}{P_{\mathrm{tot}}}\right)$,

де $P_{\text {tot }}-$ потужність падаючої хвилі.

Експериментальні дослідження поверхні світловоду [7], виготовленого із кварцового скла, показали, що спектр рельєфу поверхні має лоренцівську форму, а відповідна кореляційна функція визначається таким виразом:

$G_{\xi}(\Delta z)=G_{\xi}(0) e^{-\frac{|\Delta z|}{z_{0}}}$

Відзначимо, що кореляційна функція у такій формі використовувалася для розрахунку поверхневих втрат в фотонних кристалах [1] та нановолокнах [2], де рельєф поверхні зумовлений термодинамічно рівноважним механізмом утворення заморожених капілярних хвиль. 


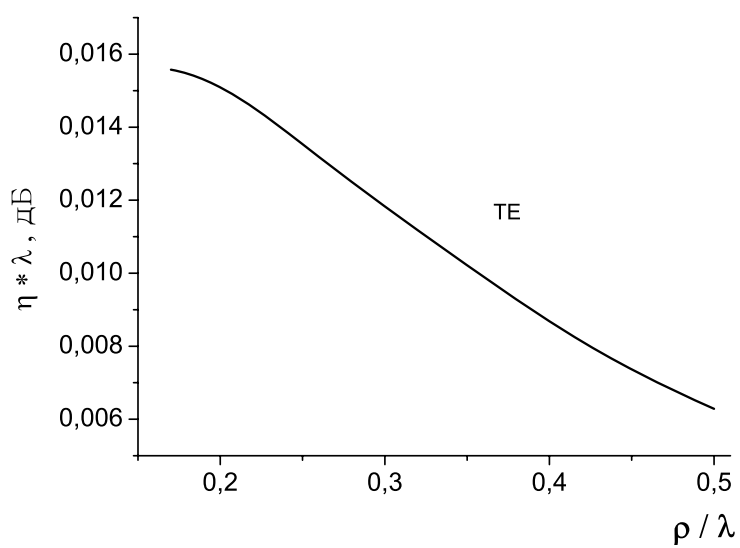

Рис. 3. Залежність коефіцієнта втрат потужності $\eta$ ТЕ моди від товщини хвилеводу $\rho$. Значення $\eta$ і $\rho$ нормовано на довжину хвилі $\lambda: \rho \rightarrow \rho / \lambda, \eta \rightarrow \eta \lambda$

\section{4. Числові результати та їх обговорення}

Числові розрахунки втрат світла у планарному хвилеводі з випадково збуреною межею поділу проведено для параметрів: $n_{c o}=1,58, n_{c l}=1,5$, довжина кореляції $z_{0}=\lambda$, дисперсія $\sigma_{\xi}^{2}=0,01 \lambda^{2}$. Розраховану залежність коефіцієнта втрат потужності для ТЕ моди від товщини хвилеводу наведено на рис. 3. При зменшенні товщини хвилеводу змінюється розподіл потужності поля направленої моди по перерізу хвилеводу, а саме: збільшується густина потужності біля меж поділу між оболонкою i серцевиною, тобто і у збуреному шарі. Тому при малих $\rho$ зі збуренням взаємодіє велика частина направленої моди. 3 іншого боку, при зменшенні товщини зменшується стала поширення направленої моди $\beta_{0}$, внаслідок чого зменшується різниця $\Delta \beta=$ $\beta_{0}-\beta_{\mathrm{ITE}}(Q)$ при $\beta_{\mathrm{ITE}}=k n_{c l}$, а отже, для вибраної моделі спектра флуктуацій рельєфу збільшується внесок низькочастотних компонент спектра. Залежності коефіцієнта втрат потужності від висоти профілю хвилеводу для ТЕ та ТМ мод наведено на рис. 4. Як і слід було чекати, спостерігається зростання втрат при зростанні висоти профілю $\Delta n=$ $n_{c o}-n_{c l}$ для обох типів мод, оскільки $P_{\mathrm{rad}} \sim\left(n_{c o}^{2}-\right.$ $\left.n_{c l}^{2}\right)^{2}$.

Залежність втрат від довжини кореляції збурень межі поділу наведено на рис. 5. Як видно, отримані залежності мають квазірезонансний характер, причому максимальне значення коефіцієнта втрат залежить від параметрів хвилеводу. Це пояснюється протилежним впливом двох факторів, які визначають ефективність розсіювання. Ефективне розсіювання
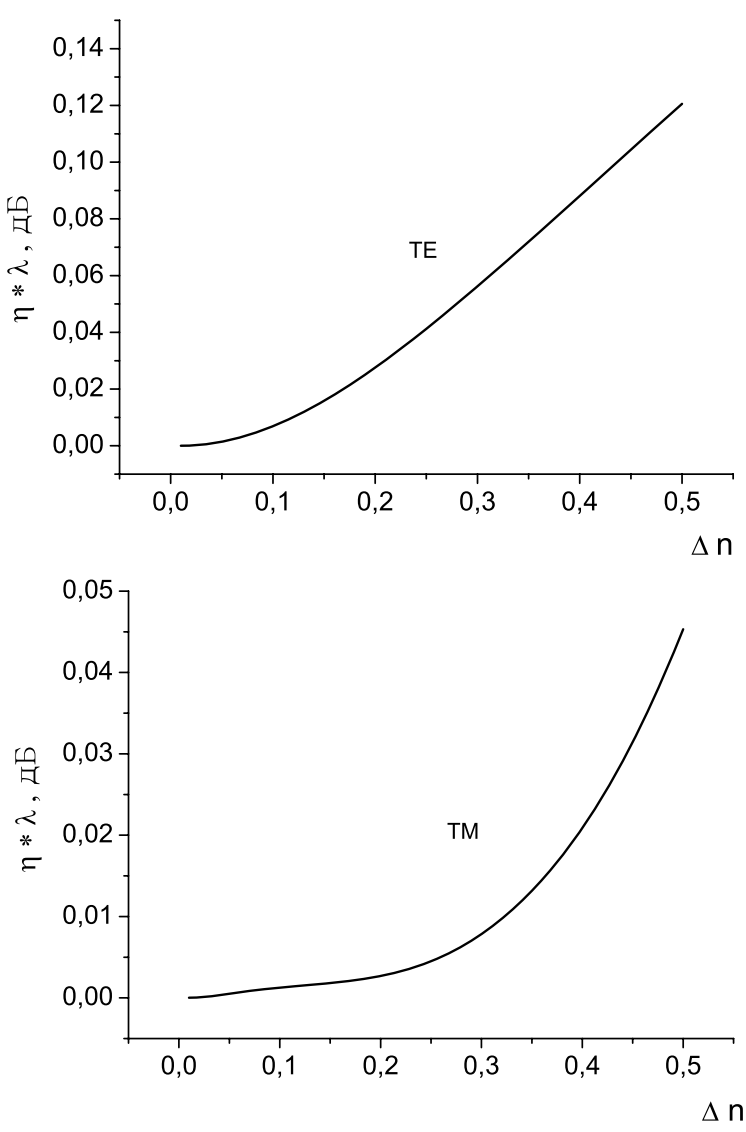

Рис. 4. Залежність коефіцієнта втрат ТМ та ТЕ моди від висоти профілю при товщині хвилеводу $\rho=0,9 \rho_{\max }$, де $\rho_{\max }=$ $\lambda / 4 \sqrt{n_{c o}^{2}-n_{c l}^{2}}-$ максимальна товщина серцевини, при якій реалізується одномодовий режим

відбувається на частотах $\Delta \beta$. За малих значень $z_{0}$ спектральна густина флуктуацій рельєфу має малу потужність розсіяння на всіх частотах, а при великих значеннях $z_{0}$ - вона має максимум на малих частотах розсіяння, тому в обох випадках на частоту розсіяння $\Delta \beta$ припадає мала потужність розсіяння. Коли $z_{0}$ відповідає частоті розсіяння $\Delta \beta$, маємо максимум розсіяної потужності. Крім того, при зменшенні товщини хвилеводу зменшується значення $\Delta \beta$. На останок відзначимо, що внесок до загального розсіяння ТМ моди другого доданка виразу (16), пропорційного квадрату кореляції, у планарному хвилеводі несуттєвий, на відміну від волоконного хвилеводу [2] (рис. 6).

Для ТЕ моди другий доданок виразу (16) дорівнює нулю, оскільки він пропорційний $\sim\left(m_{c l}-m_{c o}\right)$ і електричне поле не має розриву на межі поділу серцевина/оболонка. 


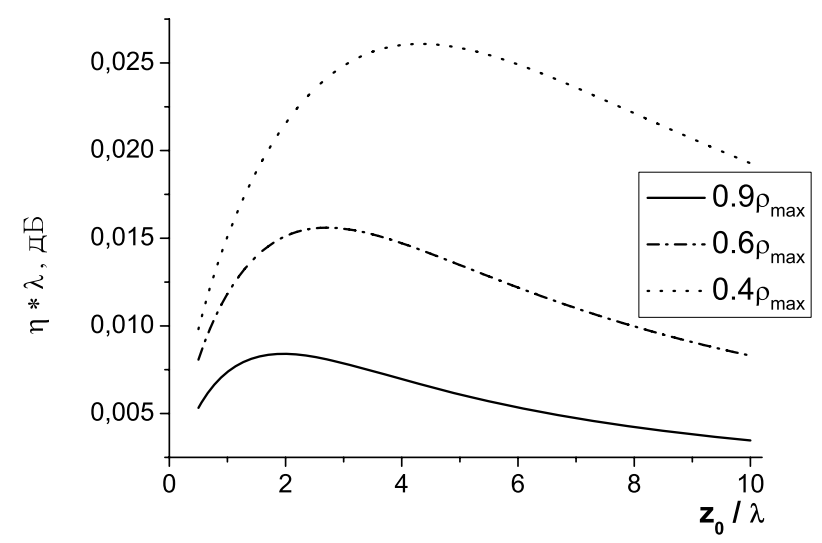

Рис. 5. Залежність коефіцієнта втрат $\eta$ ТЕ моди від довжини кореляції рельєфу межі поділу $z_{0}$. Значення $\eta$ і $z_{0}$ нормовано на довжину хвилі $\lambda$

Як бачимо на рис. 4, втрати потужності для ТМ моди набагато менші за втрати для ТЕ моди, що не відповідає даним, отриманим раніше для багатомодових хвилеводів [3]. Це можна пояснити так. Еквівалентний струм (5), співнаправлений з вектором напруженості електричного поля ТМ моди, який коливається в $x z$ площині, випромінює велику частину потужності вздовж осі $O y$, яку двовимірна модель не враховує. Водночас, еквівалентний струм для ТЕ моди коливається саме вздовж осі $O y$, тому його випромінювання цілком враховано. Таким чином, дана двовимірна модель непридатна для кількісного аналізу втрат потужності ТМ мод.

\section{5. Висновки}

Підсумовуючи, можна зробити висновок, що запропонований метод розрахунку поверхневих втрат в оптичних хвилеводах адекватно відповідає статистичному характеру задачі. Принциповою особливістю $\epsilon$ його незалежність від висоти профілю показника заломлення хвилеводу, що дозволяе проводити аналіз сильнонаправлених хвилеводних систем. Крім того, врахування нелінійних ефектів при обчисленні еквівалентних струмів істотно впливає на спектральні характеристики просторових частот рельєфу, які визначають ефективність розсіювання. Слід відзначити, що розглянутий підхід грунтується переважно на припущенні про нормальний характер статистики флуктуацій рельєфу поверхні. Однак проведені експериментальні дослідження показують, що це припущення справджується принаймні для термодинамічно рівноважних флуктуацій, які виника-
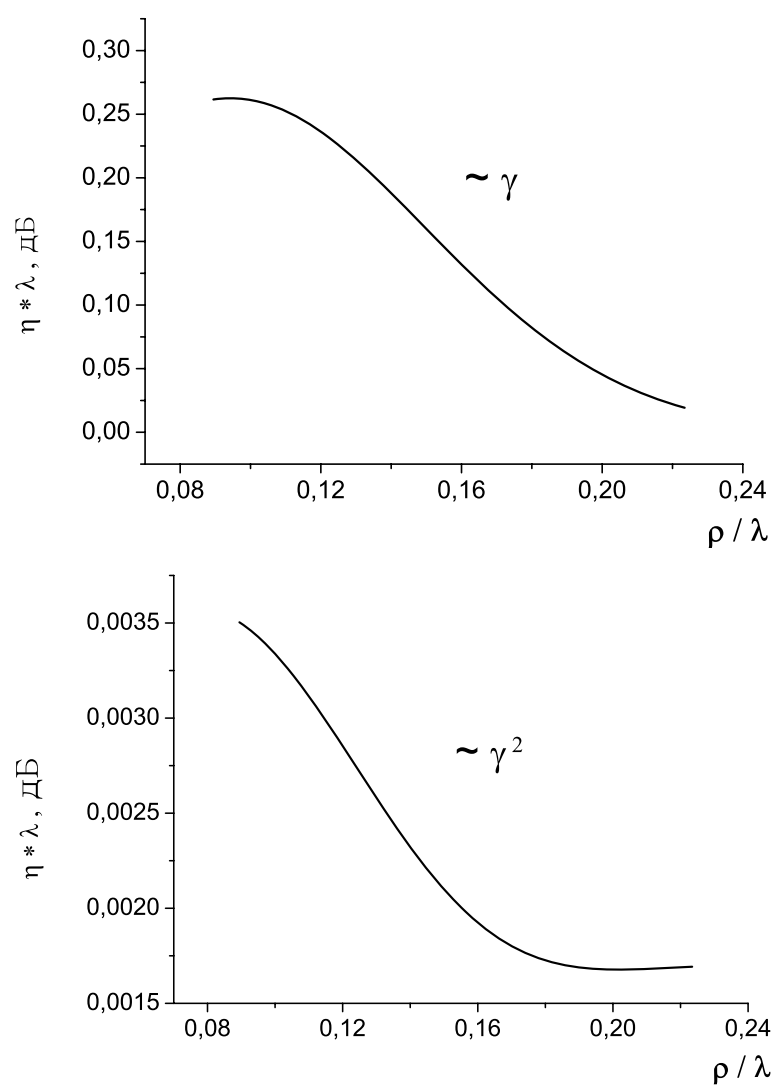

Рис. 6. Залежності коефіцієнта втрат складової ТМ моди, що пропорційна кореляції рельєфу збурення $\sim \gamma$ та квадрату кореляції $\sim \gamma^{2}$ від товщини хвилеводу

ють у технологічних процесах виготовлення хвилеводів.

Роботу виконано за підтримки Державного фонду фундаментальних досліджень України, проект № $\Phi 29.1 / 033$.

1. P.J. Roberts, F. Couny, and H. Sabert, Opt. Express 13, 7779 (2005).

2. A.V. Kovalenko, V.N. Kurashov, and A.V. Kisil, Opt. Express 16, 5797 (2008).

3. J.M. Elson, Opt. Express 9, 461 (2001).

4. J.P.R. Lacey and F.P. Payne, IEE ProceedingsOptoelectronics 137, 282 (1990).

5. А. Снайдер, Дж. Лав, Теория оптических волноводов (Радио и связь, Москва, 1987).

6. T.G. Theodoropoulos and I.G. Tigelis, Int. J. Infrared Millimeter Waves 16, 1811 (1995). 
7. A. Goriachko, A. Kovalenko, V. Kurashov, A. Shchyrba, Вісник Київського університету, серія: рідіофізика та електроніка 13, 28 (2010).

Одержано 12.05.11

РАДИАЦИОННЫЕ ПОТЕРИ В ПЛАНАРНОМ СВЕТОВОДЕ С ШЕРОХОВАТОЙ ГРАНИЦЕЙ РАЗДЕЛА МЕЖДУ ДИЭЛЕКТРИЧЕСКИМИ СЛОЯМИ

Е.Г. Матевосова, А.В. Коваленко, В.Н. Курашов

$\mathrm{P}$ е $з$ ю м е

Развита статистическая модель рассеяния света шероховатой поверхностью планарного световода, свободная от приближения слабонаправленного световода. Исследованы зависимости величины потерь от высоты профиля показателя преломления, толщины сердцевины световода и корреляционных характеристик рассеивающей поверхности. Проанализированы отличия рассеяния ТЕ и ТМ мод, показано, что двухмерная модель непригодна для количественных оценок потерь в случае ТМ мод.
RADIATION LOSSES IN A PLANAR DIELECTRIC

WAVEGUIDE WITH A ROUGH INTERFACE BETWEEN DIELECTRIC LAYERS

O.H. Matievosova, A.V. Kovalenko, V.N. Kurashov

Taras Shevchenko National University of Kyiv (64, Volodymyrs'ka Str., Kyiv 01033, Ukraine; e-mail: matyevosova.lena@gmail.com)

$\mathrm{S} \mathrm{u} \mathrm{m} \mathrm{m} \mathrm{a} \mathrm{r} \mathrm{y}$

Without the weakly guiding fiber approximation, a statistical model of light scattering by a rough surface in a planar dielectric waveguide has been developed. The dependences of radiation losses on the refractive index contrast, the waveguide core thickness, and the correlation characteristics of a scattering surface have been studied. The difference between the scattering of TE and TM modes has been analyzed, and the two-dimensional model was shown to be not suitable for quantitative estimates of losses in the case of TM modes. 